\title{
Application of MSA analysis for the evaluation of instruments for measuring the surface texture
}

\author{
Zastosowanie analizy MSA do oceny przyrządów \\ do pomiaru struktury geometrycznej powierzchni
}

\section{STANISKAW ADAMCZAK JACEK ŚWIDERSKI TOMASZ DOBROWOLSKI NUMAN DURAKBASA *}

\begin{abstract}
Presented is the application of MSA elements (measurement system analysis) for the assessment of measuring instruments that use contact and optical methods to measure surface texture. The main field of the study was the procedure of experimental deviations (bias).
\end{abstract}

KEYWORDS: surface texture, measurement system analysis

The basis for the functioning of a modern manufacturing enterprise is the use of statistical process control systems (SPC). They ensure continuous supervision over the production process and enable quick response to irregularities.

The supervisory system allows for gathering information and analyzing the course of the process, and thus preventing the occurrence of non-conformities (such as producing a product not compliant with the specification) and avoiding related losses. The main tasks of the SPC are: identifying the signal indicating the process disregulation, detecting the causes of the observed deregulation and using the obtained information to improve the process.

The quality control of products and production processes is carried out on the basis of measurement data collected during the manufacture or collection of finished products.

Analysis of MSA (measurement systems analysis) enables practical determination of numerical values of the measurement system parameters that determine the reliability of the data collected using it.

Measurement data are obtained using instruments or measuring systems that, like other man-made products, are not perfect. In fact, each $X_{\mathrm{pi}}$ measurement result obtained by means of a measuring instrument reproduces in a more or less precise way the true value $X_{0}$ of the measured quantity

\footnotetext{
* Prof. dr hab. inż. Stanisław Adamczak (adamczak@tu.kielce.pl), mgr inż. Jacek Świderski (swiderski@tu.kielce.pl), mgr inż. Tomasz Dobrowolski (t.dobrowolski@tu.kielce.pl) - Wydział Mechatroniki i Budowy Maszyn Politechniki Świętokrzyskiej; prof. dr hab. inż. NumanDurakbasa (numandurakbasa@tuwien.ac.at) - Technische Universität Wien.
}

in the form of a number. The smaller the difference $\Delta=X_{\mathrm{pi}}$ $X_{0}$, the more accurate the measurement result. To determine the level of accuracy of the measurement result, determine the value of the difference $\Delta$ between the measurement result and the reference value, which is an estimate of the true value.

In industrial practice and scientific research, the values are measured without knowing their true value, which is connected with the lack of the possibility of determining the absolute measurement error $\Delta$.

The process of measurement is influenced by many factors, including: the measurement method and procedure, the calibration procedure, the measuring instrument, environmental conditions and the metrologist [1-3]. These factors change over time and result in variability in measurement results, which is random.

This phenomenon can be observed during measurements of the same size, carried out under the conditions of repeatability with the use of a measuring instrument of appropriate resolution. With the measurement process defined in this way, the measurement results can be treated as a random variable, analyzed statistically and presented, giving their measures of position and dispersion.

If many factors influence the measurement process, none of which is decisive, the distribution of the variability of the measurement results can be described by the normal Gaussian probability distribution. The measure of the position of all possible measurement results is the average value, and the measure of dispersion - the value of the standard deviation.

Fig. 1 presents a graphical interpretation of a series of measurements. Value of the experimental standard deviation makes it possible to estimate the maximum spread of the measurement results, i.e. the range of values in which the probability of 0.997 should be the results of successively repeated measurements. 


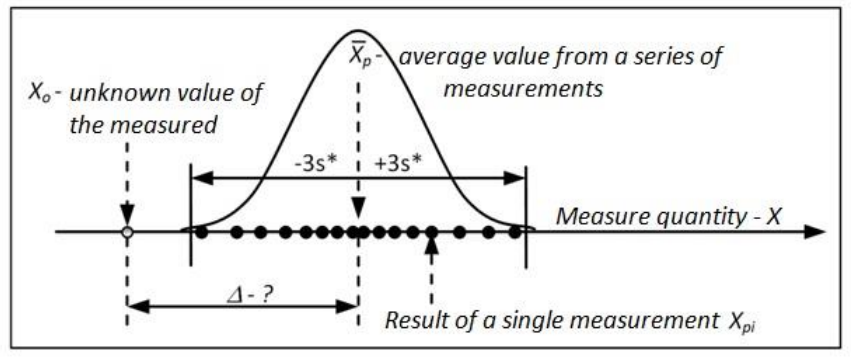

Fig. 1. Graphical interpretation of a series of measurements made under repeatability conditions

If the absolute error value $\Delta$ is not known, the assessment of the reliability of the measurement data is not fully possible. If the assumption is assumed that the metrological supervision of measuring equipment is a sufficient condition, and the absolute value of the measurement being decisive is equal to or close to 0 and negligible, it is justified to use only the R\&R procedure (repeatability and reproducibility).

Assuming that the absolute error values cannot be neglected, the R\&R analysis itself is inadequate. It is necessary to carry out a full MSA procedure, including a linearity analysis of experimental deviations. The linearity analysis uses information about the measuring instrument obtained during the experiment consisting in repeated measurements of several patterns with known $X_{\text {odn }}$ reference values, with a certain uncertainty, selected so as to cover the measuring range of the evaluated instrument at regular intervals $[4,5]$.

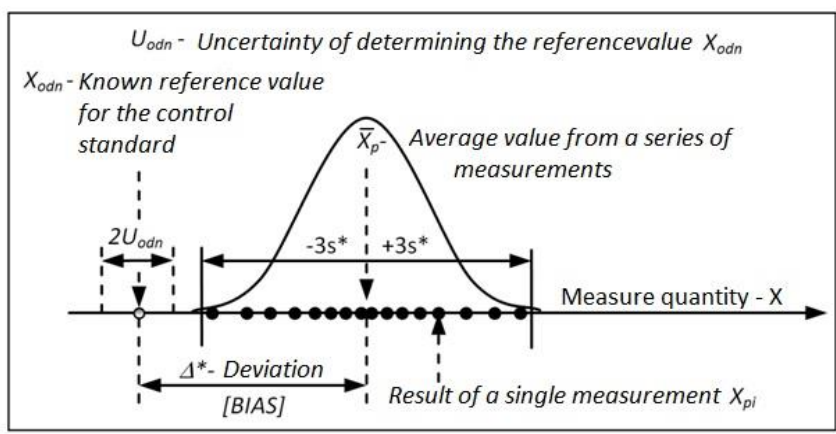

Fig. 2. Graphical interpretation of a series of measurements of the known reference value $X_{\text {odn }}$ of the control standard

From the series of measurements of each control standard, a series of measurement results is obtained, which allows to calculate the value of experimental deviation $\Delta *$ (bias) from the formula:

$$
\Delta_{i}^{*}=\bar{X}_{p i}-X_{o d n}
$$

After the experiment, a series of $\Delta_{\mathrm{ik}}{ }^{*}$ values is obtained for each control pattern on the basis of which regression analysis is performed and the linearity of the determined values of experimental deviations in the studied range can be investigated.

The latest methods of measuring the geometric structure of the surface - in accordance with the classification system presented in PN-EN ISO 25178-6: 2011 - are divided into three classes [6]:

- linear profiling methods,

- methods of spatial topography,

- methods of the integrated area.

The presented analysis concerns the first two classes of methods, because the methods belonging to the first class provide data in the form of a linear profile $z(x)$, and belonging to the second class - data in the form of spatial topography with $(x, y)$. In both of these classes of methods, the measurement consists in determining the coordinates $z(x)$ or $z(x, y)$ inequalities occurring on the surface of the measured object. For the reliability of the results, the linearity of the transducer used in the instrument is important, regardless of the method used [7].

\section{Research program}

The analysis of the linearity of experimental deviations was carried out for the following three instruments:

- contact profilometer with a conical diamond blade with a geometry of: $\alpha=90^{\circ}, r_{\text {tip }}=2 \mu \mathrm{m}$; the instrument is equipped with an interferometric head with a resolution of $0.8 \mathrm{~nm}$ and a measuring range in the $O Z$ axis of $12.5 \mathrm{~mm}$; has an active system of vibration isolation, allowing effective damping of vibrations; an $O X$ sampling rate of $0,5 \mu \mathrm{m}$ was used;

- an optical device using a coherent correlation interferometry method with a measurement range of $2.2 \mathrm{~mm}$ and a resolution of $10 \mu \mathrm{m}$ with image analysis based on a $1024 \times 1024$ pixel matrix; the tests were carried out for a magnification of $\times 10$, allowing the measurement over an area of $1.67 \times 1.67 \mathrm{~mm}$, with a sampling rate in the $O X$ and $O Y$ axes equal to $1.67 \times 1.67 \mu \mathrm{m}$;

- an open-architecture profilometric measuring device that allows the use of various types of data collection; in the research a device equipped with a confocal profilometric head with a measuring range of $140 \mu \mathrm{m}$ and a resolution of $8 \mathrm{~nm}$ was used; the minimum sampling step in the $O X$ and OY axes is $0.1 \mu \mathrm{m}$.

The analysis of the linearity of individual measurement systems was based on the measurement results of the A2/PGR standard, consisting of six grooves with depths of $h$ $=0.24 ; 0.37 ; 1.03 ; 2.41 ; 5.00 ; 9.14 \mu \mathrm{m}$, which was a known reference value. At the same time, the uncertainty of determining the reference value was known.

Fig. 3 shows the isometric image of the standard used for testing, in fig. 4 - the selected profile of the measured standard, while in fig. 5 - the method of determining the depth of the groove.

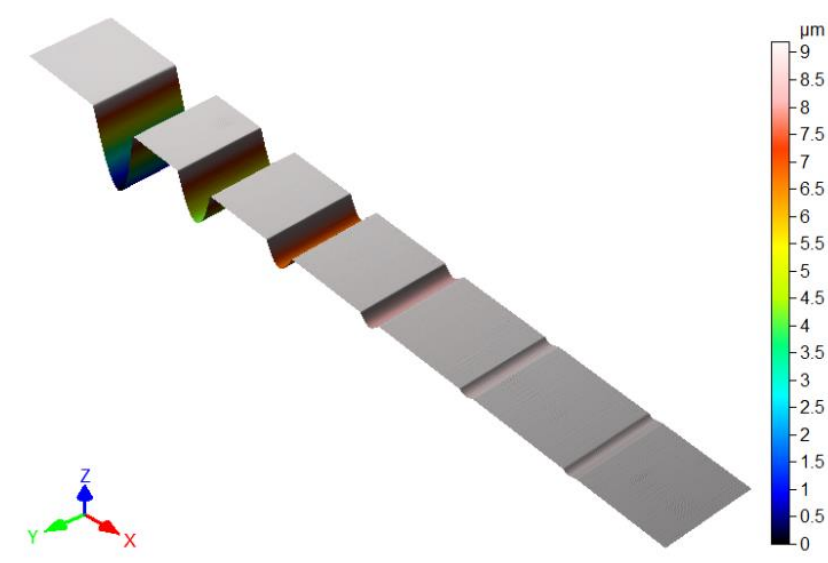

Fig. 3. Isometric image of $A 2 / P G R$ pattern

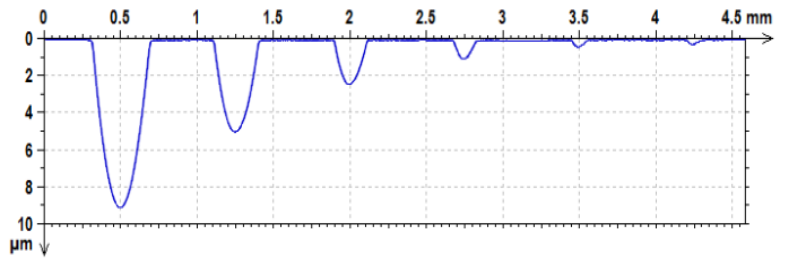

Fig. 4. Selected profile of type A2/PGR 


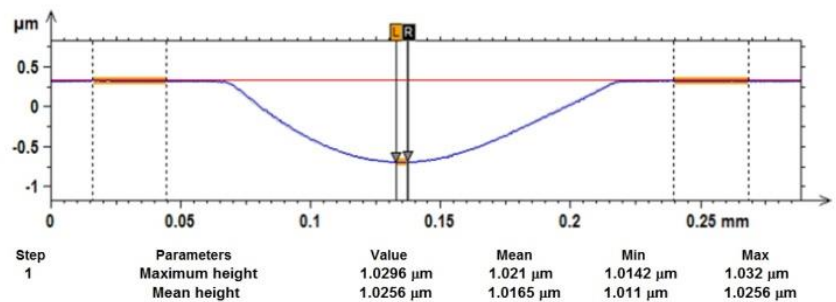

Fig. 5. Example analysis of groove depth $h=1.03 \mathrm{~mm}$

The results of three series of measurements of the A2/PGR standard made with individual instruments are presented in the tab. I.

Tab. II sets the linear regression equations and the determination coefficients for individual instruments.

TABLE I. Results of measurements of the A2/PGR standard made with individual instruments

\begin{tabular}{|l|c|c|c|c|c|c|}
\hline \multirow{3}{*}{ Type of device } & \multicolumn{7}{|c|}{ Depth of groove, $\mathrm{nm}$} \\
\cline { 2 - 8 } & 9140 & 5000 & 2410 & 1030 & 370 & 240 \\
\hline Contactprofilometer & 9082 & 4977 & 2397 & 1017 & 363 & 235 \\
\cline { 2 - 8 } & 9083 & 4,978 & 2399 & 1018 & 364 & 235 \\
\cline { 2 - 8 } & 9085 & 4,978 & 2399 & 1019 & 364 & 236 \\
\hline Interferometric & 9062 & 4964 & 2388 & 1013 & 358 & 234 \\
\cline { 2 - 8 } & 9061 & 4964 & 2389 & 1013 & 358 & 234 \\
\cline { 2 - 8 } & 9062 & 4963 & 2389 & 1016 & 358 & 233 \\
\hline Confocal & 9121 & 4963 & 2371 & 991 & 367 & 238 \\
\cline { 2 - 8 } & 9120 & 4967 & 2374 & 1007 & 372 & 227 \\
\cline { 2 - 7 } & 9126 & 4972 & 2382 & 1020 & 363 & 237 \\
\hline
\end{tabular}

TABLE II. Regression equations and determination coefficients for the analyzed instruments

\begin{tabular}{|l|c|c|}
\hline \multicolumn{1}{|c|}{ Type of device } & Regressionequation & $R^{2}$ \\
\hline Contactprofilometer & bias $=-0,00542 \cdot X-0,0026$ & 0,94 \\
\hline Interferometric & bias $=-0,00747 \cdot X-0,0059$ & 0,97 \\
\hline Confocal & bias $=-0,00131 \cdot X-0,0016$ & 0,09 \\
\hline
\end{tabular}

The results of linearity analysis of experimental deviations for individual instruments are presented in figs. 68.

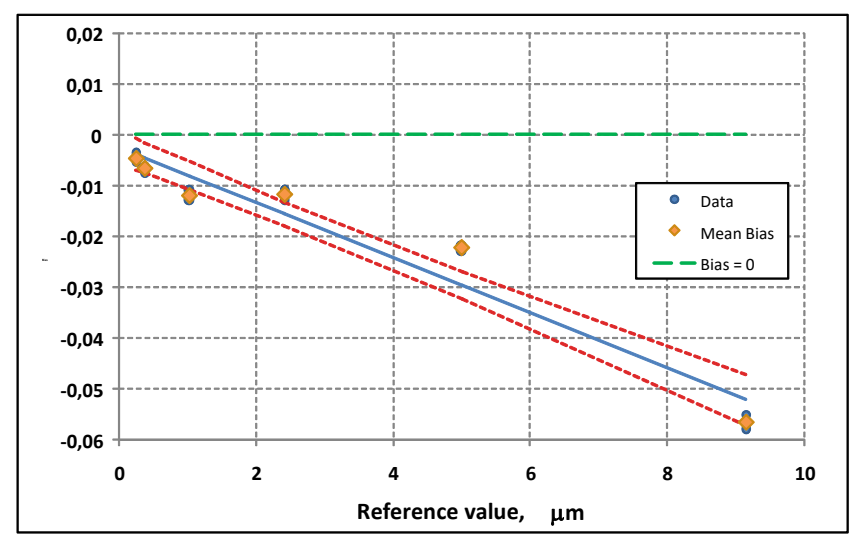

Fig. 6. Linearity analysis of experimental deviations for a contact profilometer with a mating blade

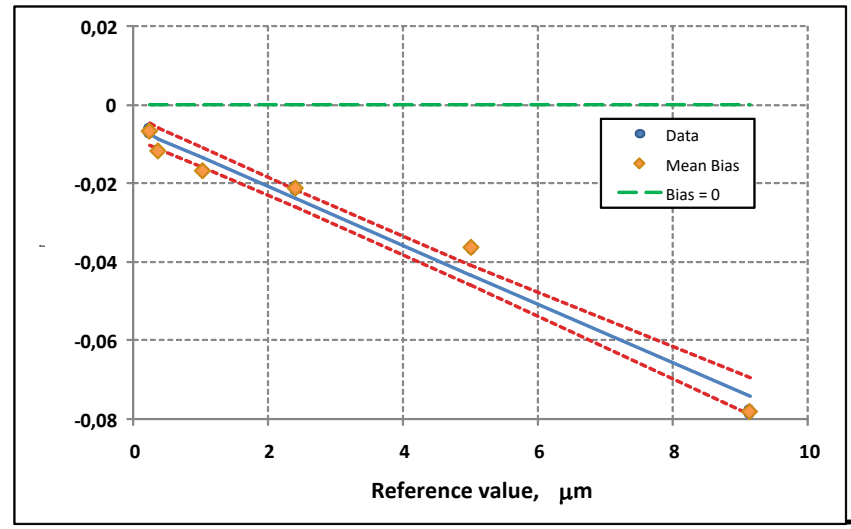

Fig. 7. Linearity analysis of experimental deviations for an optical instrument using the coherent correlation interferometry method

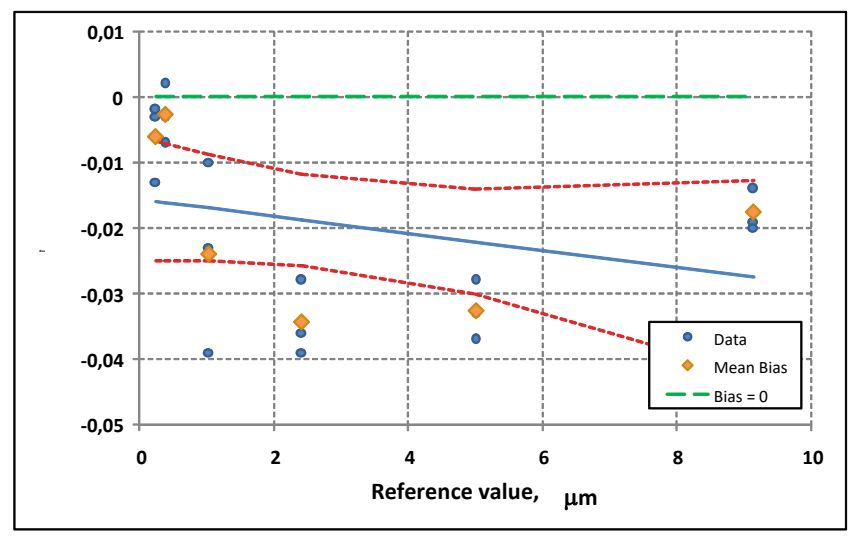

Fig. 8. Linearity analysis of experimental deviations for a linear profiling device with a confocal sensor

\section{Conclusions}

The R\&R procedure takes into account the deviations $\Delta$, which introduce individual instruments, indicates the direction in relation to the true value of the measured value, but does not allow to determine the absolute value of this deviation. Only the analysis of linearity enables the determination of a simple regression of experimental deviation, which can be used to introduce a correction of results or be necessary information to build a budget of measurement uncertainty. Cyclic repetition of the linearity analysis at specified time intervals gives information about the stability of the measurement system.

In the case of all analyzed devices for measuring the geometric structure of the surface, a negative directional coefficient of straight regression was obtained, which means that the values of the coordinates of vertical inequalities will be smaller than the real values.

The modulus of the linear regression coefficient for a device with confocal head has the smallest value, which could indicate a small deviation $\Delta$, but on the other hand, a small value of the regression coefficient $R^{2}=0.09$ does not allow an unambiguous evaluation of the obtained results.

Publication based on the results of the research within the PBS2 project financed from the National Center for Research and Development (No PBS2/A6/20/2013) "Research and assessment of reliability of modern methods of measuring surface topography in the micro and nano scale". 


\section{REFERENCES}

1. Adamczak S. „Pomiary geometryczne powierzchni. Zarys kształtu, falistość i chropowatość". Warszawa: WNT, 2008.

2. Miller T., Adamczak S., Świderski J., Wieczorowski M., Łętocha A., Gapiński B. "Influence of temperature gradient on surface texture measurements with the use of profilometry". Bulletin of the PolishAcademy of Sciences. 65, 1 (2017): pp. 53-61 (online: 2.17.2017).

3. Pawlus P., Wieczorowski M., Mathia T. "The errors of stylus methods in surface topography measurements". Szczecin: ZAPOL, 2014.

4. Tabisz R. "Creating accuracy of industrial measurement systems for their intended use". Joint International IMEKO TC1+ TC7 Symposium. 21-24.09.2005. Ilmenau, Germany.

5. PKN-ISO/IEC Guide 99 - Międzynarodowy słownik metrologii. Pojęcia podstawowe i ogólne terminy z nimi związane (VIM)

6. PN-EN ISO 25178-70:2014 - Geometrical product specification (GPS) - Surface texture - Part 70: Material Measures.

7. Giusca C., Leach R. "Calibration of the metrological characteristics of areal contact stylus instruments". Measurement Good Practice Guide. No. 129 (2013). NationalPhysicalLaboratory. ISSN 1368-6550.

Translation of scientific articles, their computer composition and publishing them on the website www.mechanik.media.pl by original articles in Polish is a task financed from the funds of the Ministry of Science and Higher Education designated for dissemination of science. 